\title{
The painful knee after total knee arthroplasty
}

\author{
R. Becker $\cdot$ M. Bonnin $\cdot$ S. Hofmann
}

Published online: 29 July 2011

(C) Springer-Verlag 2011

This issue will provide a comprehensive overview about pain after total knee arthroplasty (TKA). It is one of the most difficult issues after TKA. How can we best treat patients who experience persistent pain? Unfortunately, we might see an increasing number of patients with unexplained pain after TKA in the near future, due to the constantly increased number of patients undergoing primary TKA. Two major reasons appear to be responsible for the increased number of TKA. First of all the population is getting older and it has been estimated that approximately $25 \%$ of the entire population will be older than 65 years in 2050. Second, the patients are nowadays more demanding in terms of activities of daily life. The world has to face a huge economic burden in the near future in order to treat patients suffering from osteoarthritis [10]. Primary and revision TKA increased approximately 300 and 220\%, respectively, between 1991 and 2004 causing an explosion of costs from 5 to 15 billion USD with regard to primary TKA in the United States. It has been estimated that the number of primary TKA will rise up to 3-4 million and revision TKA up to 270,000 annually [6].

Patient's expectation in TKA is very high. Eighty-five per cent of the patients expect to be completely pain free after TKA, but according to a recent study, unfortunately only $43 \%$ of them are fully pain free after surgery showing a remarkable discrepancy [7]. We are aware of a huge

\author{
R. Becker $(\bowtie)$ \\ Brandenburg, Germany \\ e-mail: roland_becker@yahoo.de \\ M. Bonnin \\ Lyon, France \\ S. Hofmann \\ Vienna, Austria
}

variety of surgeon- and patient-related factors, which may have significant influence patient's outcome. Many factors may cause persistent pain after TKA. In a recent and comprehensive overview by Seil et al. on factors related to chronic pain after TKA, they distinguished between biological and mechanical intra-articular factors and extraarticular factors. Sometimes, there is also a combination of factors. There is need for a clear diagnostic algorithm due to the complexity and the variety of factors, which are responsible for persistent pain after TKA. This algorithm should be routinely performed in every patient complaining of chronic pain and low function. However, in several patients, it may be extremely difficult to identify the cause of patient's non-satisfaction. Surgical exploration after TKA revealed that only $45 \%$ of the patients had problems related to their implants [8]. This is an interesting fact, which strongly indicates that even further development in prosthetic design, for instance to improve kinematics and function will not entirely solve the problem. The number of co-morbidities prior to surgery can to some extent predict pain after TKA surgery. But, what about pain referred from the spine or hip? Further factors, such as female gender, younger age at the time of surgery and depression, appear to be associated with increased risk of pain after TKA [3]. Reduced mental well-being has also shown a worse shortterm outcome [11].

Besides the focus on the knee and adjacent joints, we need to pay even more attention to patient's mental health, in order to better identify patients, who may show an increased risk for non-satisfaction after surgery.

However, and despite the fact that some of the patients are not completely satisfied and not completely pain free after TKA, this procedure is well accepted as an effective and successful end-stage procedure in patients with knee osteoarthritis for relieving chronic pain and functional 
disability. Considering the return to normal activity after TKA, which are the most important activities the patients expect? A recent study has shown that stretching exercise, kneeling and gardening are the most appreciated activities [12].

However, not only activities during daily living are important. Patients also enquire frequently about the option to return to sports after joint replacement. Approximately $10 \%$ of patients at the age of 75 years still participate in sport on a regular basis [2]. Fitness, Nordic walking and golf are popular after knee arthroplasty. Hooper et al. [5] reported a return to sport in $63.7 \%$ after TKA and in $96.7 \%$ after UKA at a resuming time of about 4 month. Similar results in return to sport after UKA are shown by other researchers [9]. A high percentage of patients reported normal knee function when performing swimming (77\%), golf $(65 \%)$, stationary biking (64\%) and stretching exercise (61\%) [12]. In general, patient's sport activity appears to be at a lower level and with less extend. Activity at the older age is important for mental health and for improvement and maintenance of cardiovascular function [4]. In contrast, inactivity will cause overweight, loss of aerobic fitness, coordination, muscle mass, and osteoporosis will be very likely [1].

Taken together, total joint replacement can be seen as one of the greatest achievements in the orthopaedic world.

\section{References}

1. Barry HC, Eathorne SW (1994) Exercise and aging. Issues for the practitioner. Med Clin North Am 78:357-376
2. Bonnin M, Laurent JR, Parratte S, Zadegan F, Badet R, Bissery A (2009) Can patients really do sport after TKA? Knee Surg Sports Traumatol Arthrosc

3. Bourne RB, Chesworth BM, Davis AM, Mahomed NN, Charron KD (2010) Patient satisfaction after total knee arthroplasty: who is satisfied and who is not? Clin Orthop Relat Res 468:57-63

4. Coudert J, Van Praagh E (2000) Endurance exercise training in the elderly: effects on cardiovascular function. Curr Opin Clin Nutr Metab Care 3:479-483

5. Hopper GP, Leach WJ (2008) Participation in sporting activities following knee replacement: total versus unicompartmental. Knee Surg Sports Traumatol Arthrosc 16:973-979

6. Kurtz S, Ong K, Lau E, Mowat F, Halpern M (2007) Projections of primary and revision hip and knee arthroplasty in the United States from 2005 to 2030. J Bone Joint Surg Am 89:780-785

7. Mannion AF, Kämpfen S, Munzinger U, Kramers-de Quervain I (2009) The role of patient expectations in predicting outcome after total knee arthroplasty. Arthritis Res Ther 11:R139

8. Mont MA, Serna FK, Krackow KA, Hungerford DS (1996) Exploration of radiographically normal total knee replacements for unexplained pain. Clin Orthop Relat Res:216-220

9. Naal FD, Fischer M, Preuss A, Goldhahn J, von Knoch F, Preiss S, Munzinger U, Drobny T (2007) Return to sports and recreational activity after unicompartmental knee arthroplasty. Am J Sports Med 35:1688-1695

10. Ong KL, Mowat FS, Chan N, Lau E, Halpern MT, Kurtz SM (2006) Economic burden of revision hip and knee arthroplasty in medicare enrollees. Clin Orthop Relat Res 446:22-28

11. Walton MJ, Newman JH (2008) Pre-operative mental wellbeing and the outcome of knee replacement. Knee 15:277-280

12. Weiss JM, Noble PC, Conditt MA, Kohl HW, Roberts S, Cook KF, Gordon MJ, Mathis KB (2002) What functional activities are important to patients with knee replacements? Clin Orthop Relat Res 404:172 